\title{
Management and Psychological Aspect: Teenagers' Awareness of Privacy in Social Media
}

\author{
http://dx.doi.org/10.25008/jkiski.v5i2.429 \\ Eni Maryani ${ }^{1}$, Detta Rahmawan $^{2}$, Irma Garnesia $^{3}$, Reksa Anggia Ratmita ${ }^{4}$ \\ ${ }_{1,2,3,4}$ Faculty of Communication Sciences - Universitas Padjadjaran \\ Jl. Raya Bandung - Sumedang KM 21, Jatinangor, West Java 45363 - Indonesia \\ *Corresponding author: eni.maryani@unpad.ac.id
}

Submitted: November 10, 2020, Revised: December 04, 2020, Accepted: December 15, 2020

Accredited by Kemristekdikti No. 28/E/KPT/2019

\begin{abstract}
Rising concern about the impact of internet usage among teenagers needs to be continuously addressed. Teenagers' awareness of online privacy was the focus of this study on account of frequent sharing of private information in social media. This study is an exploratory research which tries to map and understand the psychological and cultural aspects of vulnerable online privacy practice by teenagers. The data were collected through a survey and interviews with high school students in Bandung, Indonesia. This study found that teenagers' knowledge, awareness, and management of online privacy was relatively low. Psychologically, teenagers often need others to talk to. To maintain relationship, some cultural aspects, such as togetherness, friendliness, and openness to strangers were perceived as important. However, those aspects were the causes of poor online privacy practices. A call for increased media literacy and the development of cyber law that can anticipate internet-based crime especially against teenagers, were discussed.
\end{abstract}

Keywords: Social media, media literacy, online privacy, teenagers, impact of internet

\section{Introduction}

In Indonesia, internet penetration among teenagers is considerably high with teenagers using the internet primarily for social media $(87 \%)$, online browsing $(68.7 \%)$, and instant messaging (59, 9\%) (APJII, 2014). The high use of social networking by internet users in Indonesia portraits a very high social interaction by internet users with their social environment. The use of the internet itself provides a vast space and free opportunities to interact with anyone, anywhere and anytime. The opening of their social network to the wider network is not only a positive thing but also can cause problems in their relationship. It is happening if the relation through media is not understood differently from their face to face relationship with people that they know directly.

In February 2014, UNICEF with Kominfo and Harvard University conducted a study entitled "Internet Usage among Children and Adolescents in Indonesia." They tracked online activities of children and adolescents involving 400 respondents aged 10 to 19 years across Indonesia. From this study, there are 30 million children and teens or about $80 \%$ who use the internet. The study found that many children and teenagers provide private information such as a home address, telephone number, or school address to the masses online (Unicef, 2014).

Social networking like internet has provided an indispensable method of communication and ignores geographical and cultural barriers. Beside this, it has some adverse effects also like cyberbullying and crimes against children, risks of fraud or identity theft, and invasion in privacy (Saini et al., 2020). KPAI pointed that from 20112015 there were 1032 cases of cybercrime and pornography that befell children and adolescents aged 0 to 18 years (KPAI 2015). Again, it happens 
because children and teenagers often upload their private information on social media.

Lawrence Lessig wrote a book about Free Culture: How Big Media Uses Technology and The Law to Lock Down Culture and Control Creativity to describe this phenomenon. It explained that the Internet had formed a very free culture, it leaves content open for expansion by others, even our private information (Lesig, 2004). This statement becomes highly relevant to discuss teenagers' understanding of privacy in the social media.

Social media is becoming very popular among all ages indeed. It makes it easier for users to interact and share information, and also point that social media has obscured the personal distance/privacy boundary within a person (Trepte, 2011). The convenience provided by social media makes users unaware of the dangers that can arise from online privacy issue. Private information that we have such as date of birth, telephone number, home address, school address, and the names of family members are easily known and also abused.

The cases such as photo theft on Facebook or Instagram for cyberbullying, cyber-stalking, sex transactions fraud, chat sex services, phone sex, commercial purposes, and fraud are the dangers that lurk social media users, particularly teenagers.

Study shows that the motives of teenagers on the internet are for status gaining, opinion expression, social interactions, information gaining, pastime, and entertainment (Luthfia, 2019). Teenagers use social media as a means of self-actualization. Information sharing is at the core of getting attention for yourself and getting approval from your peers. Being in the social media is the proof of their existence, I tweet, therefore I am (Streep, 2013). The need for selfactualization ultimately impacts on over-sharing (over sharing of information). Teenagers as middle adolescent have not been able to control information that may and should not be shared in social media. Rickman (2018) studied how the teenagers participate in an "attention economy" they assess the risks and advantages of using social media when it comes to their popularity and privacy (Cordon, 2020)

According to their social media use, Line Messenger is a popular social media among teenagers. Based on the survey collected from 3,891 people, ranging from 13 to 44 years old, it is known that teens aged 15 to 18 years prefer Line Messenger more (Marsono, 2014). Known to be one of Japan's most famous mobile apps, Line Messenger is perceived more attractive with stickers, games, and timeline features. Facebook is less likely being used because their parents are also on Facebook.

The high use of Line Messenger among teenagers in Indonesia and the rising concern over online privacy issue have made this study have a prominent place in privacy related to the risks lie behind the screen such as; cyberstalking, online fraud, identity fraud, and private information theft. In regards to the phenomena, this study aims to explore the awareness of privacy among teenagers, particularly high school students in Bandung, West Java Province, in the use of Line Messenger as their ultimate social network.

We focused on LINE as a social media platform through the following considerations: LINE, which initially emerged as an application primarily used as instant messaging applications, is now used by young people in Indonesia not only to communicate and interact through private and group messages, but also as an application for various activities which resemble the use of social media, one of which is as a place of selfexpression, seeking information, seeking entertainment, and also establishing online networks.

In this context, LINE has become similar to the other popular social media platforms such as Facebook, Twitter and Instagram. However, unlike other social media, LINE is a private social media. When LINE is used not only as an instant messaging application, the risks associated with privacy in the context of socialization and online social interaction also emerge.

\section{Theoretical Framework}

Privacy described by Irwin Altman (1975) as a selective process of controlling access to self and others. While Westin's theory of privacy, on the other hand, describes the way people temporarily limiting access of others about their information to protect themselves (Westin, 1967). Disclosing personal information is however considered an inherent need in humans, so much so that it can be addictive, as demonstrated by Tamir and Mitchell (2012) in a clinical study (Oghazi, 2020). Sharing information is the most common pathway to social media. According to a narrow interpretation, sharing any personal information on social media could be equated with giving up one's privacy (De Wolf, 2020).

Pew Research Center Study, USA, shows that most teenagers share information to gain attention and acceptance for themselves. It also happens in Indonesia, in this case, teenagers love to upload photos to view comments from their friends. The more "Like" or comments they get, the more they feel popular (Bialik \& Matsa, 2017). 
There will be personal satisfaction if teenagers are popular in social media.

The form of popularity they seek is what Langlois Ganaele indicated as self-actualization. Ganaele in his book Meaning in The Age of Social Media determines the popularity and narcissistic behavior in the social network as selfmeaningfulness. There is a financial value attached to the self, and social network realm calls it as selfmeaningfulness. Ganaele also mentioned that seeking for the true meaning of the self is part of self-actualization itself (Langlois, 2014).

However, self-actualization by teenagers impacts on over-sharing (abundance sharing of information). Teenagers have not been able to control the private information they share on social media. It gets worse as technological advances make social media similar to the outside world where we cannot control the flow of information, personal distances, and extensive interactions with family, friends, and the public (Trepte, 2011).

It is regrettable that the self-existence teenagers seek has put aside other fundamental needs, namely privacy. Teenagers grow up surrounded by a wide range of social media platforms and most of them are both consumers and creators of content in them. However, they are not always aware or have a limited perception of the implications of theirs online actions and the risks that they can encounter (Alemany, 2020). Balancing the privacy and self-disclosure in the era of social media is a daunting task. On the one hand, openness to the surroundings is essential for a social function and a self-balance (Trepte, 2011).

A person needs to disclose to bond with others, maintain good relationships, and be accepted into his social environment. However, regarding the social environment, every human being also has the right to privacy. It means that even if they have parents, relatives, friends or other closest people to talk to and share something, they also have few things that are considered as their private information. Every individual is free to organize their personal sphere, including their private information.

Referring to the above phenomena, subsequently, the discussion of privacy in this study will refer to Communication Privacy Management (CPM) Theory by Sandra Petronio. This theory explains how one manages privacy and understands the meaning of privacy. Developed in 2002 by Sandra Petronio, this theory explains the process used to manage one's private information; how covering and disclosing private information may pose risks and benefits (West \& Turner, 2010).

This theory stands as the basic concept of how teenagers manage their private information. Five basic concepts from the theory which will be used are private information, private boundaries, controls and ownership of private information, rules-based management systems, and dialectics disclosure (West \& Turner, 2010).

Communication privacy management theory seek to understand the way people decide to disclose information about themselves in the context of interpersonal relationships. Furthermore, Metzger in his research on privacy in the case of e-commerce stated that despite some contexts difference between face-to-face and computer-mediated communication (CMC) contexts, CPM theory can be implemented in the online context (Metzger, 2007). Online privacy concerns do in fact influence people's actions with regard to privacy management. Examples of privacy management are restricting privacy settings on one's social media account, disclosing less information, and even reducing social media usage frequency (Oghazi, 2020). However, we only include our discussion to online social media context.

CPM is also popular on Social Network Site such as Twitter. The concept of multiple privacy layer is often seen as an "onion" which has multiple dimensions (Annie Jin, 2013). Twitter and Line have similarities in terms of platform used for sharing information. According to a study conducted in Samarinda, Indonesia, it was found that the effects of Line usage on adolescents also proved to be related to the aspects of change and formation of attitude. These changes involve emotions related to pleasure, anger and sadness (Fitrianur, 2016).

Based on these findings it means that the information shared on the Internet also concerns personal matters. Hence, privacy issues on the use of Line is interesting to be analyzed. Teenagers especially high school and college students are rapid SNS users. Study which examined privacy concerns on college students related to their Twitter usage behaviours found that Control and Boundary Rules of Private Information significantly predict time spent on Twitter. Nevertheless, the same CPM variables did not predict other usage behaviours (Yang, Pulido, \& Kang, 2016).

In addition to referring to the use of CPM theory related to different contexts, this study also refers to the theory of self from psychology and anthropology which defines in detail the 
differences between self-constructs independently and interdependently. Independent selfconstructions are owned by people in western culture and are also often referred to as egocentric, individualist, autonomous, separate, idiocentric, and self-contained (Markus \& Kitayama, 1991).

Meanwhile Markus and Kitayama assume that people in eastern culture tend to collectivism develop interdependent constructs that are also relevant called connected, constitutive, collective, holistic, sociocentric, ensemble, contextualist, allocentric, and relation. Although at the beginning Markus and Kitayama referred to independent and interdependent concepts but from the results of his research related to the constructive implications of themselves towards them concluded that in nondependence people still account for others.

The link of social characteristics and social media usage in teenagers is also expressed in a study of international students in the US about their social media usage that is associated with social support and adjustment, which reveals that those students feel that their social media usage positively related to the level of social adjustment but is negative in terms of social support. International students feel uncomfortable to discuss their difficulties through social media because there is a complex 'culture internetworking' in their online networking environment (Seo, Hyuniin, et all, 2016). Communication norms and patterns will depend on the function and the type of each culture. If the adaptation ability is not possessed, then what will happen is a feeling of being lazy to connect with people who come from different cultures (Widiastuti \& Ritonga, 2020)

Social media succeeds in influencing many teenagers to embrace modern culture full of -isms such as relativism, individualism, emotionalism, presentism (present-time ism), materialism, autonomy, victimism. These -isms will produce the attitude which is no longer critical to social media negative effects, even indifferent attitude, no selfcontrol, consumptive, selfish, indifferent to the applicable rules (Tarigan, 2017). Some social media sites turn out to have a strong effect on quality of human life and habits and sacrifice mental health and our time for playing social media (Widiastuti \& Ritonga, 2020).

\section{Material and Methodology}

This study uses the exploratory research through a questionnaire survey and depth interviews to garner the data and analyze the findings. To systematically assess the data about teenagers, particularly the high school students, we took four high schools in Bandung as the population. We performed the multistage cluster sampling to determine four high schools in Bandung and decided on Senior High School 1 Bandung, Vocational High School 2 Bandung, Senior High School Al-Falah Bandung, and Private High School Pasundan 2 Bandung.

Based on the preliminary data of Line Messenger users in those schools, 126 students were arranged to fill in the questionnaires. The respondents were comprised of $69.04 \%$ boys and $30.95 \%$ girls. Their age ranged from 15 to 18 years, of which $33.3 \%$ were aged $15,54.76 \%$ were aged $16-17$, and $11.9 \%$ were aged 18-19. The researchers also conducted in-depth interviews with some of the students to dig deep and get a profound analysis of evidence. Lastly, the researchers also conducted a descriptive quantitative analysis through frequency distribution and multiple cross tabulation.

\section{Result and Discussion}

In line with the important concepts elaborated by Petronio and data obtained, the results of this research will be presented in several themes. In the beginning, the initial discussion will be related to the pattern of personal information sharing carried out by teenagers on social media. This pattern will be a basic understanding of why there are dilemmas and limitations of teenagers to manage their personal information on social media. Based on the discussion about the problems faced by adolescents related to their habits and how to use their personal data on social media, it will then influence their understanding of data management and management. Finally, as Petronio said, we will discuss the dialectics related to the management carried out with regard to the disclosure or concealment of personal information on social media. Petronio's privacy management concept also focused on the dialectics related to the costs and benefits, and consideration of how one's information will be owned, and also its potential to be used and spread by others (Petronio \& Reierson, 2009).

Based on the questionnaires, it is known that teenagers use the internet at special costs. Most respondents $(89.68 \%)$ have spent special funds to 
access the internet via mobile phone, and other respondents $(10.31 \%)$ only use the internet at the unpaid (available for free) internet access (Wi-Fi) from their mobile phones.

As for the duration of Line Messenger usage, there is a considerable number of respondents (47.61\%) who access this messenger for more than two hours per day. Only a small number of respondents $(28.57 \%)$ stated that they access less than one hour each day and there are $23.8 \%$ of respondents who access this Japan's popular messenger between 1 and 2 hours per day. To put this data in context, the researchers observed that some respondents routinely access the Line Messenger from their smartphones.

Those respondents claimed they use Line Messenger for chatting with their classmates, best friends, watching some funny videos on the newsfeed, and reading light news. Most of the respondents also actively add new friends to expand their connection, even if they do not know who they are. This study also found that some respondents are eager to update their status or change their profile picture just to make it more attractive and to show they are active users.

It is interesting to note that from the interviews, teenage girls use the messenger for sharing more than boys do. Boys are more likely to play the games provided by this platform.

\section{Sharing Private Information in Social Media}

The content of concealing and revealing is what we call the private information, drawn from Petronio's concept on discrepancies between private information to disclosure, which are not aligned with self-disclosure (Petronio, 2002).

Issuing the massive usage of Line Messenger through the mobile phone, the researchers are keen to explore more of this internet usage. It is necessary to explore whether the massive use of online conversation through Line Messenger is coupled with the ability of respondents to manage their private information. Through the collected data, this study reveals the information regarding the openness of respondents to their private information to their friends and others, even unknown persons.

It is critical to note because the respondents perform a habitual activity in using the internet through a very personal device, this means that they go online every day with their personal device and unconsciously disseminate their private information online. Their online activities also occur in a relatively routine and intensive duration, $71.41 \%$ of the respondents have a regular habit of using the internet for more than 1 hour every day.

Table 1. Tendency to Share Private Information in Social Media

\begin{tabular}{|c|c|c|}
\hline No. & Category & Percentage \\
\hline 1 & Low & $7,14 \%$ \\
\hline 2 & Medium & $38,09 \%$ \\
\hline $\mathbf{3}$ & High & $\mathbf{5 4 , 7 6 \%}$ \\
\hline \multicolumn{2}{|c|}{ Total } & $100 \%$ \\
\hline
\end{tabular}

Three categories of Low, Medium, and High are used to measure the tendency of sharing personal information among teenagers. In this category, the tendency of the teenagers to share personal information is high $(54.76 \%)$.

The heavy internet users who accounted for $54.76 \%$ of the respondents, are accustomed to sharing their private information with friends, acquaintances, even unknown people they meet online. The study found that almost all respondents share their real names, real photos, school names, birth dates, and cities where they live in Line Messenger. One respondent revealed that "I often tell [personal information] that someone asks or sometimes I also just write it to be known to friends." For the respondent, this act of sharing personal information is not problematic because according to her, "my friends also talk about their [personal information] to me" or in another word, her friends also do the same things. Simply put, they exchange information related to private information and have a surprisingly high rate of openness. Of the 126 students included in this study, only a few respondents $(7.14 \%)$ could be categorized carefully engaged with their private information. They share a little piece of their private information and do not attempt to violate their friends' privacy rights by sneaking a peek at their friends' private information. McQuail (2005) once stated that when a person has access to technology that connects with a large number of people, they must master the characteristic of the 
mass which is public and can reach massive audiences in a short time.

\section{The Dilemma of Private Information Boundaries among Teenagers}

Private boundaries are the second element of CPM theory. It is a division between private information and public information (Petronio, Ellemers, Giles, \& Gallois, 1998).

Related to the above concept, this study explores the data related to the private boundaries of respondents in keeping or revealing private information about themselves. Users primarily should be able to manage the private information upon using social media. Sharing private information with friends and people around them through social media is a risky activity and more prominently, diminishes the private value from the information itself.

Table 2 elaborates respondent's attitude toward the ownership of private information. $59.5 \%$ express their respects for their friends' private information, and $11.9 \%$ do not disagree with having other people's private information. Most respondents (61.9\%) believe their friends will keep their private information secure, but nearly $33.3 \%$ of the respondents are in doubt whether their friends or those they have shared their private information will guard their information. Our analysis also found $3.2 \%$ respondents who do not believe their private information are safe if they share them with

their friends and other people. Apart from those who believe that their friends will keep their private information, there are $73 \%$ who limits their private information in Line Messenger. Interestingly, we found $18.2 \%$ who stated their uncertainty whether or not they have disclosed all private information to their friends. A small number of respondents think it is safe to disclose their private information to anyone. Most respondents (89.7\%) agree it is best to limit their private information in the timeline status.

Table 2. Attitude toward The Ownership of Private Information

\begin{tabular}{|c|l|c|}
\hline No. & \multicolumn{1}{|c|}{ Description } & Percentage \\
\hline 1 & Respects for their friends' private information & $59.5 \%$ \\
\hline 2 & Do not disagree with having other people's private information & $11.9 \%$ \\
\hline 3 & Believe their friends will keep their private information secure & $61.9 \%$ \\
\hline 4 & $\begin{array}{l}\text { In doubt whether their friends or those they have shared their } \\
\text { private information will guard their information }\end{array}$ & $33.3 \%$ \\
\hline 5 & $\begin{array}{l}\text { Do not believe their private information are safe if they share them } \\
\text { with their friends and other people }\end{array}$ & $3.2 \%$ \\
\hline 6 & Believe that their friends will keep their private information & $73 \%$ \\
\hline 7 & $\begin{array}{l}\text { Uncertain whether or not they have disclosed all private } \\
\text { information to their friends }\end{array}$ & $18.2 \%$ \\
\hline 8 & It is best to limit their private information & $89.7 \%$ \\
\hline
\end{tabular}

In response to the questionnaire about limiting or not limiting private information shared on Line Messenger, more than half (66.7\%) are categorized as having a medium level in keeping their private information. This means they have some confidential information that they do not share to the general public or their friends, but sometimes they do occasionally share because they believe their friends will keep that information safe. A respondent revealed that disclosing some confidential information to close friends is something he needs to do.

Petronio, Giles, Gallois \& Ellemer (1998) argues that a person usually keeps private information for himself, and at times, he opens some of his private information to others to maintain his social relationships. Retrospectively, according to Petronio, certain private information that is later given to other people may be disclosed to maintain their social relationships or friendships.

Only a few are unwilling to disclose private information to their friends and surroundings $(8.73 \%)$. These people will usually be considered as introverts and are assumed to have a less open social relationship with others. In addition, this attitude is also considered not in accordance with the values adopted by the community. This is evidenced by the expression of respondents who stated that "it is not polite if we are asked and do not want to answer, including [questions on] personal information". 
Therefore, their awareness to limit sharing their private information with the general public is seen as socially self-limiting. In a collective culture like Indonesia, it is necessary to control the attitude of collective society who easily share their daily activity, and even private information online and perceived social media as the place to put their daily activity online. This means that the co-owned private information becomes publicly available and it has the possibility of it being duplicated or distributed to other parties in a matter of seconds far and wide. The potential of some information to spread quicker, and further in social media than any other medium means that there are no guarantees that information can be well maintained by the coowners because it is not only owned by individuals anymore, but it is now part of a system as well as the masses.

\section{The Barriers in Controlling Private Information}

People think that they own their private information and also have rights to control it. Their ability to organize and control their private information is the concept of Control and Ownership in Communication Privacy Management Theory. According to Petronio, teenagers who have their private information feel entitled to control who can know the information (Petronio, Ellemers, Giles, \& Gallois, 1998).

Based on research data, it is known that their ability to control and take ownership is in the medium category $(60,31 \%)$. The data shows that although respondents convey their private information to their friends, they also realize that they have to keep some of the information for themselves. We also found that $35.7 \%$ respondents choose which friends to disclose their private information, $48.4 \%$ felt bothered with personal chat from unknown person, and $47.6 \%$ however still agree to be opened in a social relationship.

Their reluctance in sharing private information suggests their ability to control the information they want to reveal or conceal to others. This respondent's habit can be perceived to be related to psychological conditions in the adolescent phase (Duane, 1991). In the adolescent phase, teenagers often experience vulnerable times where they are psychologically confused to set boundaries over their personal space or letting someone into it (Petronio, 2002).

Somehow, they want to be noticed by their peer group, but on the other hand, they often reject others' curiosity through their personal space.
Surprisingly, there is a considerably small proportion of the respondents $(32.5 \%)$ who can already control their private information.

To elaborate, some respondents already have the capability to decide which information may be revealed and which information should be concealed. But the reason is not only because they have the skills to manage their personal data. Some do limit information because of psychological reasons or feelings of dislike. One respondent said "I often do not tell about data or information about myself because I don't like it". In other words, there are two important things related to this. Firstly, it may be the psychological aspect and the adolescent phase as favoured by Duane (1991). Secondly, they need to increase their basic knowledge that would become the foundation of their competence to consciously decide how, as teens, they can manage their private information that they may share on the internet. Hence, there need to be more efforts to provide knowledge for teens to gain competence in managing their private information when using the internet.

\section{Rules in Managing Private Information}

There is a set of rule posits before a person wants to share his private information or let others enter his personal sphere. Petronio includes three criteria on this element; privacy rule characteristics (a set of rules consisting of culture, gender, motivation, context, and the risks and benefits that cause a person to reveal or conceal), boundary coordination (preliminary approval applied to both receivers), and boundary turbulence (when the second party leaked the private information of the first party) (Petronio, Ellemers, Giles, \& Gallois, 1998).

Taking the privacy rule characteristics, respondents have been sharing private information with their friends from the same origins $(57.9 \%)$, the same type of sex (61.1\%), specific motive or purpose $(67.4 \%)$, certain context/circumstance (76.1\%) and particular benefits (68.2\%). To make matters worse, $65.9 \%$ respondents do not think before risking their private information with others through social media. However, we found $68.3 \%$ respondents who ask their mates' consideration before revealing their private information to peer groups or others. Furthermore, nearly $57.1 \%$ claimed to have no purpose or specific benefits when revealing their private information, and $82.5 \%$ share their private information just to maintain a good relationship with their friends. 
This is as expressed by a respondent "I share information on personal matters because I want to maintain good relations with my friend... because I also know her" In maintaining good relationships, different types of relationships also affect the type of information that most respondents $(73 \%)$ share.

Most respondents (81\%) claimed to be committed to safeguarding their friends' private information and $89.7 \%$ respondents were very upset when their friends leaked their private information. Disappointment not only occurs when their private information was being revealed but also when their friends refused to listen to their problems $(49.2 \%)$ or ignore their problems (48.4\%). Based on the data acquired, $54.76 \%$ of the respondents fall into the category of medium skills in managing private information according to rules attached to CPM theory. However, 20.63\% respondents still manage to apply highly strict privacy rules related to CPM theory.

To recapitulate, it can be understood if we refer to the psychological condition of the respondents which can be categorized as the Middle adolescent. In this phase, someone is still struggling to discover their identity (Duane, 1991). Psychologically, adolescents have yet to find their own self-concept or identity. Therefore, they tend to be spontaneous and dislike strict rules or any form of regulations, even rules they have to decide for themselves. Supporting teens during this situation can be done by strengthening their personal values or cultural norms they believe in yet also be cautious. For example, a culture that demands credibility, and guards them to maintain appropriate ethics or avoid causing shame among society, therefore, they must be careful and consider everything, every risk, and benefit in all of their actions including in sharing their private information through the internet. Things they must consider upon making decisions rely on rules they make for themselves, regarding private information they have, that is also part of what they have to consider before sharing with others.

In reference to these values, efforts to build their awareness of the importance of rules and regulations or values must be taken into account when they manage their private information used, for example, in the social media, is highly needed.

\section{Dialectic Disclosure Among Teenagers}

Based on the data finding, it is known that most respondents (76.2\%) experience internal conflicts upon deciding whether or not to convey private information. In response to the question: Do you regret sharing your private information? Up to $42.3 \%$, respondents admit they sometimes regret their decision on disseminating their private information. Based on interviews, these respondents admitted their regret caused them to be more cautious in conveying their private information. On the other hand, most respondents $(55.6 \%)$ say they have no regret, meaning they do not care about the information that they revealed to others. In reference to the issues above, $46 \%$ of the respondents have a medium ability to overcome dialectic problems related to the need to share private information.

On the other hand, $40 \%$ of the respondents are still afraid, in doubt, and sometimes regret after passing on their private information. Of all the respondents, only $46 \%$ can deal with dialectic disclosure, which means they can decide whether the information will be owned, used, or spread. Another sizable percentage (40\%) are still in doubt or regret their disclosure on social network sites.

This indicates that although in the beginning, they are aware that private information should not be spread to others through social media, but in the event that it had already happened they do not think twice about it anymore. They assume once it is communicated it is something of the past, so it has passed. They are unaware that what they had conveyed is now in a digital format that can be duplicated or distributed and may pose a future conflict if resurfaced. Communication through the media, especially social media is not an interpersonal or a face-to-face communication that is undocumented and has limited exposure.

According to data, it indicates the fact that most respondents need someone else to talk to or at least the opportunity to disclose private information. This issue will be solved when the respondents find a close friend who can listen and keep the private information within their circle. Some of the respondents expressed that they find closure by writing diaries or personal blogs. However, they do not realize their private information, albeit in the form of a diary, has been documented and digitized so it will be difficult to keep it as their very own secret.

\section{Conclusion}

The intensity of Line Messenger use is used not only to build relationships but also to expand relationships with previously unknown people. Simply put, various parties are connected with 
teenagers through Line Messenger. The results presented here shows that the use of online messenger as a social media among teens is quite intensive. Besides, the use of Line Messenger requires cost allocation among adolescents. They have to set up some funds to stay connected to the internet and routinely access their Line Messenger account.

This study built upon Petronio's concept of Communication Privacy Management (CPM) theory shows there are findings related to five aspects of CPM theory: knowledge of private information, private boundaries, control and ownership, rule-based management systems, and dialectic disclosure that occur in relation to the disclosure of private information. Regarding the understanding of private information, most respondents understand the concept of private information, either their own or others.

Moreover, most respondents also have certain restrictions and attitudes towards private information. While some teenagers believe their friends will safely keep their private information, they still restrict and never put their private information on a status update. Respondents' ability to control private information is still in the medium category. It is more or less related to the lack habit of respondents in establishing rules to manage their private information and personal space.

Some literature and research link the psychological condition of teenagers with their attitudes and behavior towards private information in social media, such as Matthews, Derlega \& Morrow (2010), Stutzman \& Kramer-Duffield (2010), and Yang (2016). Based on this research, it is known that respondents' attitudes related to private information are also related to the norms or cultural values of the community they are in.

The research findings reveal that their culture underlies the belief that their openness also determines social relationships between a person and his or her friends regarding private information. Therefore, there is a motive for the disclosure of private information as an attempt to establish good relations with the social environment. This is related to Indonesian or eastern culture as a social context of research that emphasizes the concept of 'togetherness.' Therefore, some teenagers of social media users in Indonesia are accustomed to including personal data in their Line Messenger or other social media accounts.
Media literacy education and communication privacy management concepts are needed for teenagers. This is due to the open access to digital media supported by technological developments and increased access of adolescents to the internet (the existence of economic support or increased welfare), the unstable psychological condition, the value of the eastern culture. On the other hand, it is found that competence among adolescence in making barriers for their private information is still limited and the lack of rules they have in managing private information especially in social media needs to be further addressed.

Indonesian society with its eastern culture which is socially more open or friendly to foreigners, and has a high level of social media usage, becomes a society vulnerable to internetbased crime, mainly through the social media. Such conditions require more serious efforts to develop a cyber law that can anticipate the development of Internet-based crime, especially against teenagers and children.

\section{Acknowledgements}

The author(s) received no financial support for the research, authorship, and publication of this article. We thank all of our colleagues who provided support and valuable insight in completing this article.

\section{References}

Alemany, J., Delval, E., \& Garcia-Fornes, A. (2020). Assessing the Effectiveness of a Gamified Social Network for Applying Privacy Concepts: An Empirical Study with Teens. IEEE Transactions on Learning Technologies. https://doi.org/10.1109/TLT.2020.3026584

Altman, I. (1975). The environment and social behavior: privacy, personal space, territory, crowding. Monterey: Brooks/cole.

Annie Jin, S.-A. (2013). Peeling back the multiple layers of Twitter's private disclosure onion: The roles of virtual identity discrepancy and personality traits in communication privacy management on Twitter. New Media \& Society. 15, 813-833.

APJII, P. (2014). Asosiasi Penyelenggara Jasa Internet Indonesia. Jakarta: APJII.

Bialik, K., \& Matsa, K. E. (2017, OCtober 4). Key trends in social and digital news media. Retrieved Otober 21, 2017, from http://www.pewresearch.org/fac t- 
tank/2017/10/04/key-trends-in-social-anddigital-news-media/ Duane, S. (1991). Psikologi Pertumbuhan Model-Model kepribadian Sehat. Yogyakarta: Penerbit Kaninus.

Cordon, S. (2020). Aimee Rickman: Adolescence, Girlhood, and Media Migration: US Teens' Use of Social Media to Negotiate Offline Struggles. Journal of Youth and Adolescence.

https://doi.org/10.1007/s10964-020-012202

De Wolf, R. (2020). Contextualizing how teens manage personal and interpersonal privacy on social media. New Media and Society. https://doi.org/10.1177/1461444819876570

KPAI. (2015, June 14). Pelaku Kekerasan Terhadap Anak Tiap Tahun Meningkat. Retrieved from KPAI: http://www.kpai.go.id/berita/kpai-pelakukekerasan-terhadap-anak-tiap- tahunmeningkat/\#

Langlois, G. (2014). Meaning in The Age of Social Media. London: Palgrave Macmillan.

Lesig, L. (2004). Free Culture: The Nature and Feature of Creativity. New York: Penguin Group.

Luthfia, A. (2019). The Analysis of Indonesian Teenagers' Motives for Using the Internet. Proceedings of 2019 International Conference on Information Management and Technology, ICIMTech 2019. https://doi.org/10.1109/ICIMTech.2019.884 3760

Marsono, C. (2014, September 4). What Social Medias Are Indonesians Using? (2014 Data). Retrieved from LinkedIn: https://www.linkedin.com/pulse/whatsocial-medias- indonesians-using-2014data-chandra-marsono

Markus, Hazel Rose dan Shinobu Kitayama (1991). Culture and the Self."Implications for Cognition, Emotion, and Motivation, Psychological Review, Vol. 98, No. 2, 224253 0033-295X/91/

Matthews, A., Derlega, V., \& Morrow, J. (2006). What is Highly Personal Information and How Is It Related to Self-Disclosure Decision-Making? Communication Research Reports. 23 (2), 85-92.

McQuail, D. (2005). Mass Communication Theory. $\left(5^{\text {th }}\right.$ Edition). London: Sage Publications

Oghazi, P., Schultheiss, R., Chirumalla, K., Kalmer, N. P., \& Rad, F. F. (2020). User self- disclosure on social network sites: A crosscultural study on Facebook's privacy concepts. Journal of Business Research. https://doi.org/10.1016/j.jbusres.2019.12.00 6

Petronio, S. (2002). Boundary of Privacy: Dialectics of Disclosure. Albany, NY: SUNY Press.

Petronio, S., \& Reierson, J. (2009). Regulating the Privacy of Confidentiality: Grasping the Complexities through Communication Privacy Management Theory. Uncertainty, Information Management, and Disclosure Decisions: Theories and Applications. In T. A. Afifi, Uncertainty, Information Management, and Disclosure Decisions: (pp. 365-383). New York: Routledge.

Petronio, S., Ellemers, N., Giles, H., \& Gallois, C. (1998). (Mis)communicating Across Boundaries: Interpersonal and Intergroup Considerations. Communication Research, 571-595.

Tarigan, R. E. (2017). Determination of Adolescent Worldview: Combating Negative Influence of Social Media. Jurnal Komunikasi Ikatan Sarjana Komunikasi Indonesia. https://doi.org/10.25008/jkiski.v2i1.91

Saini, N., Sangwan, G., Verma, M., Kohli, A., Kaur, M., \& Lakshmi, P. V. M. (2020). Effect of Social Networking Sites on the Quality of Life of College Students: A CrossSectional Study from a City in North India. Scientific World Journal. https://doi.org/10.1155/2020/8576023

Seo, Hyunjin, at all, (2016). International Students' social media use and social adjustment. [S.1.], oct. 2016. ISSN 13960466. Available at: $<$ https://firstmonday.org/ojs//index.php /fm/article/view/6880/5646>. Date accessed: 26 jan. 2019. Doi https://doi.org/ 10.5210/ fm.v21i11. 6880.

Streep, P. (2013, June 25). 4 Things Teens Want and Need from Social Media. Retrieved October 21, 2017, from Psychology Today: https://www.psychologytoday.com/blog/tec h-support/201306/4-things-teens-want- andneed-social-media

Stutzman, F., \& Kramer-Duffield, J. (2010). Friends Only: Examining a PrivacyEnhancing Behavior in Facebook. Conference on Human Factors in Computing Systems, (pp. 1553-1562). Atlanta. 
Trepte, S. a. (2011). Privacy Online: Perspectives on Privacy and Self-Disclosure in the Social $W e b$. New York: Springer.

Unicef, K. (2014, February 18). Siaran Pers Tentang Riset Kominfo dan UNICEF Mengenai Perilaku Anak dan Remaja Dalam Menggunakan Internet. Retrieved from Kominfo.go.id:

http://kominfo.go.id/index.php/content/detai 1/3834/Siaran+Pers+No.+17-PIH-

KOMINFO-2-

2014+tentang+Riset+Kominfo+dan+UNIC $\mathrm{EF}+$ Mengenai+Perilaku+Anak+dan+Remaj $\mathrm{a}+$ Dalam+Menggunakan + Internet $+/ 0 /$ siaran pers\#.Vt1v_5yLTIU

West, R., \& Turner, L. (2010). Introducing Communication Theory: Analysis and Application. Boston: McGraw-Hill.

Westin, A. (1967). Privacy and freedom. Bodley Head: New York.

Widiastuti, T., \& Ritonga, R. (2020). Ethnomethodology Study of Digitalized
Social Communication Apprehension in Basmala Youth Community Members. Jurnal Komunikasi Ikatan Sarjana Komunikasi Indonesia. https://doi.org/10.25008/jkiski.v5i1.362

Yang, K. C., Pulido, A., \& Kang, Y. (2016). Exploring the Relationship between Privacy Concerns and Social Media Use among College Students: A Communication Privacy Management Perspective. Intercultural Communication Studies, Vol. 25 Issue 2, 4662. 